\title{
Anti-inflammatory effect of ozonated krill (Euphausia superba) oil in lipopolysaccharide-stimulated RAW 264.7 macrophages
}

Hong-Deok Kim", Soo-Bin Lee ${ }^{1}$, Seok-Chun Ko², Won-Kyo Jung ${ }^{2,3}$, Young-Mog Kim ${ }^{1,2}$ and Seon-Bong Kim ${ }^{1 *}$

\begin{abstract}
Background: Inflammation has been known to associate with many human diseases. The objective of this study was to evaluate an anti-inflammatory effect of ozonated krill (Euphausia superba) oil, which was prepared by the treatment of krill oil using ozone gas. The anti-inflammatory activity was evaluated in lipopolysaccharide (LPS)-stimulated RAW 264.7 macrophages.

Results: Ozonated krill oil significantly inhibited nitric oxide (NO) production and suppressed the mRNA and protein expression of inducible nitric oxide synthase (iNOS) and cyclooxygenase-2 (COX-2) in LPS-stimulated RAW 264.7 macrophages. Ozonated krill oil also reduced the mRNA expression of inflammatory cytokines such as interleukin (IL)-1 $\beta$, IL-6, and tumor necrosis factor (TNF)-a in LPS-stimulated RAW 264.7 macrophages. To elucidate the mechanism underlying the anti-inflammatory activity of ozonated krill oil, we evaluated the effects of ozonated krill oil on the activation of mitogen-activated protein kinases (MAPKs) pathway. Ozonated krill oil suppressed the LPS-stimulated phosphorylation of p38 MAPK and c-Jun N-terminal kinases (JNK).

Conclusion: This study revealed that the ozonated krill oil exhibited an anti-inflammatory effect in LPS-stimulated RAW 264.7 macrophages. To the best of our knowledge, this is the first report that ozonated krill oil suppressed pro-inflammatory mediator and cytokine expression in LPS-stimulated RAW 264.7 macrophages by inhibiting the phosphorylation of p38 MAPK and JNK.
\end{abstract}

Keywords: Ozonated krill oil, Anti-inflammatory, RAW 264.7 macrophages, MAPKs

\section{Background}

Krill (Euphausia superba) oil has recently attracting more interest because of its unique compositions and health benefits including protection against cardiovascular disease (CVD) (Berge et al. 2014). The fatty acids in krill oil are composed of approximately $30-65 \%$ of phospholipid form whereas the fatty acids of other fish oil are mainly triglycerides (Tou et al. 2007). In addition, the krill oil possesses high content of unsaturated fatty acids (UFAs, 48.6\%) of which contains high amount of omega-3 fatty acids such as docosahexaenoic acid

\footnotetext{
*Correspondence: owlkim@pknu.ac.kr

'Department of Food Science and Technology, Pukyong National University,

45, Yongso-ro, Nam-gu, Busan 48513, Republic of Korea

Full list of author information is available at the end of the article
}

(DHA, 16.6-36.5\%) and eicosapentaenoic acid (EPA, 11.1-24.8\%) (Virtue et al. 1995). Moreover, minor components such as astaxanthin, sterols, vitamin A, and tocopherols are also present in krill oil (Xie et al. 2017). According to the previous reports, krill oil, an extract prepared from a species of Antarctic krill, E. superba, has emerged with health benefits, including neuroprotection, anti-oxidant, anti-inflammation, anti-obesity, and improvement of metabolic disorders due to its omega-3 fatty acids, phospholipid-derived fatty acids, and the natural pigment, astaxanthin (Barros et al. 2014; Berge et al. 2013; Costanzo et al. 2016; Fasano et al. 2014; Lee et al. 2015). In addition, krill oil is known to have higher antioxidant potency compared with fish oil (Zhu et al. 2015). As like these reasons, the krill oil has 
been attracting interest as an attractive resource to develop novel food stuff or ingredients.

Ozone has been utilized in many fields such as being a disinfectant, an anti-inflammatory agent, and agent for improvement of regional circulation, simulation of regenerative process, and painless procedure (Deutsch 2007; Nogales et al. 2008). Ozone reacts with the double bonds of polyunsaturated fatty acids (PUFAs) to form reactive oxygen species (ROS) and bioactive products (Valacchi et al. 2013). Ozonated oils have been reported being applied in diverse diseases including burns, wound healing, inflammation, and periodontitis (Campanati et al. 2013; Guerra-Blanco et al. 2017; Shoukheba and Ali 2014; Valacchi et al. 2013). However, the above studies employed ozonated land plant oils, and there remains a lack of data regarding the biological studies of marine-derived oils by ozone treatment. Therefore, the objective of this study is to evaluate an anti-inflammatory effect of krill oil by ozone treatment on lipopolysaccharide (LPS)-stimulated RAW 264.7 macrophages and to elucidate the action mechanisms of anti-inflammatory effect.

\section{Methods}

\section{Materials}

Antarctic krill used in this study was captured in Antarctic Ocean provided in frozen state by Dongwon Industries Co. (Busan, Korea) and stored in a freezer at $-20{ }^{\circ} \mathrm{C}$. Dulbecco's modified Eagle's medium (DMEM), fetal bovine serum (FBS), penicillin, streptomycin, and other materials needed for culturing cells were obtained from Gibco BRL Life Technologies (Grand Island, NY, USA). Griess reagent, 3-(4,5-dimethyl-thiazol-2-yl)-2,5-diphenyltetrazolium bromide (MTT), and lipopolysaccharide (LPS) of Escherichia coli 026:B6 were purchased from SigmaAldrich (St. Louis, MO, USA). Anti-phosphorylated JNK (anti-p-JNK; Cat. NO. 9251), anti-JNK (Cat. NO. 9252), anti-phosphorylated ERK1/2 (anti-p-ERK1/2; Cat. NO. 9101), anti-ERK1/2 (Cat. NO. 9102), anti-phosphorylated p38 (anti-p-p38; Cat. NO. 9211), anti-p38 (Cat. NO. 9212), anti-COX-2 (Cat. NO. 4842), and anti-iNOS (Cat. NO. 2982) mouse or rabbit antibodies were purchased from Cell Signaling Technology (Beverly, MA, USA). AntiGAPDH (Cat. NO. sc-25,778) antibodies were purchased from Santa Cruz Biotechnology Inc. (Santa Cruz, CA, USA). The other chemical reagents were of analytical grade.

\section{Preparation of ozonated krill oil}

The first step in krill oil preparation was to lyophilize the whole body of krill and mix it with hexane in a 1:4 ratio. The mixture was allowed to precipitate for $4 \mathrm{~h}$, and the supernatant was extracted. The supernatant was then mixed with hexane in a 1:2 ratio, followed by precipitation and filtration. Subsequently, the extracted supernatant was mixed with hexane in a 1:1 ratio, followed by precipitation and filtration. The extracted oil was treated with ozone gas at $3.006 \mathrm{~g} / \mathrm{h}$ using an ozone generator for $144 \mathrm{~h}$. The ozonated krill oil was dissolved in DMSO with $2 \%$ tween 80 and then used for experiments, adjusting the final concentration of DMOS with $2 \%$ tween 80 in culture medium to $<0.1 \%$. Also, untreated group or LPS-stimulated group was treated with DMSO with $2 \%$ tween 80 of the same volume instead of ozonated krill oil.

\section{Cell culture}

The murine macrophage cell line RAW 264.7 was purchased from the Korean Cell Line Bank (Seoul, Korea). RAW 264.7 macrophages were cultured in DMEM supplemented with $10 \%$ heat-inactivated FBS, $100 \mu \mathrm{g} / \mathrm{mL}$ streptomycin, and $100 \mathrm{U} / \mathrm{mL}$ penicillin. The cells were then incubated in an atmosphere of $5 \% \mathrm{CO}_{2}$ at $37{ }^{\circ} \mathrm{C}$.

\section{Measurement of cell viability using the MTT assay}

The cell viability was conducted by the MTT assay as described by Mosmann (1983). RAW 264.7 macrophages were seeded in a 96-well plate and incubated aliquots of the ozonated krill oil at $37{ }^{\circ} \mathrm{C}$ for $24 \mathrm{~h}$. The MTT stock solution was subsequently added to each well and incubated for $4 \mathrm{~h}$. The formazan crystals in each well were dissolved in $100 \mu \mathrm{L}$ of DMSO, and the absorbance was measured using microplate reader (BioTek Instruments, Inc., USA) at $540 \mathrm{~nm}$.

\section{Determination of nitric oxide (NO) production}

Nitric oxide (NO) production in the culture medium was measured via the Griess reaction (Weissman and Gross 2001). After a 24 h pre-incubation of RAW 264.7 macrophages with various concentrations (10, 50, and $100 \mu \mathrm{g} / \mathrm{mL}$ ) of ozonated krill oil and stimulation with LPS $(1 \mu \mathrm{g} / \mathrm{mL})$, the quantity of nitrite accumulated in the culture medium was measured as an indicator of NO production. Specifically, $100 \mu \mathrm{L}$ of supernatant from each well was mixed with $100 \mu \mathrm{L}$ of Griess reagent (1\% sulfanilamide and $0.1 \%$ naphthylethylenediamine dihydrochloride in $2.5 \%$ phosphoric acid), and the absorbance at $540 \mathrm{~nm}$ was measured in a microplate reader. Fresh culture medium was employed as a blank in every experiment.

\section{Western blot analysis}

Western blot analysis was conducted to protein expression as described by Kim et al. (2016). RAW 264.7 macrophages were seeded in a 96-well plate and incubated with LPS $(1 \mu \mathrm{g} / \mathrm{mL})$ coupled with aliquots of the ozonated krill oil at $37{ }^{\circ} \mathrm{C}$ for $24 \mathrm{~h}$. Then, the cells were collected and washed twice with PBS. The cells were lysed in lysis buffer for $60 \mathrm{~min}$ and then centrifuged at $12,000 \mathrm{rpm}$ and $4{ }^{\circ} \mathrm{C}$ for $15 \mathrm{~min}$. The protein 
concentrations were determined using the $\mathrm{BCA}$ protein assay kit (Thermo Fisher Scientific, IL, USA). The lysate containing $20 \mu \mathrm{g}$ of protein was subjected to electrophoresis on a sodium dodecyl sulfate (SDS)-polyacrylamide gel, and the gel was transferred onto a nitrocellulose membrane. The membrane was blocked with 5\% non-fat dry milk in Tris-buffered saline with $0.1 \%$ Tween 20 (TBS-T) for $1 \mathrm{~h}$. The primary antibodies were used at a 1:1000 dilution. The membrane was shaken with the primary antibodies at $4{ }^{\circ} \mathrm{C}$ for overnight, washed with TBS-T, and then contacted with the secondary antibodies at 1:3000 dilutions. The signals were confirmed using an enhanced chemiluminescence (ECL) western blotting detection kit (Amersham Pharmacia Biotech, Little Chalfont, UK) and estimated using the Multi Gauge V3.0 software (Fujifilm Life Science, Tokyo, Japan).

\section{Reverse transcription-polymerase chain reaction (RT-PCR) analysis}

RT-PCR analysis was conducted to determine the mRNA expression as described by Kim et al. (2016). The total ribonucleic acid (RNA) from the RAW 264.7 macrophages treated with LPS in the presence or absence of ozonated krill oil was extracted using the TRIzol reagent. Equal amounts of RNA were used for each complementary deoxyribonucleic acid (cDNA) synthesis reaction. Adjusted oligo dT primers $(10 \mu \mathrm{M})$ were added and then cooled with ice. The isolated messenger ribonucleic acid (mRNA) was then used to synthesize cDNA according to the manufacturer's instruction (Promega, Madison, WI, USA). Single-stranded cDNA was amplified by PCR using specific primers. The primer sequences used to amplify the desired cDNA fragment were as follows: cyclooxygenase-2 (COX-2) forward and reverse primers: 5' - TGA AAC CCA CTC CAA ACA CA -3' and 5'GAG AAG GCT TCC CAG CTT TT -3'; inducible nitric oxide synthase (iNOS) forward and reverse primers: 5' - CAC CTT GGA GTT CAC CCA GT -3' and 5'- ACC ACT CGT ACT TGG GAT GC -3'; interleukin-1 $\beta$ (IL-1 $\beta$ ) forward and reverse primers: $5^{\prime}$ CTG TCC TGC GTG TTG AAA GA $-3^{\prime}$ and $5^{\prime}-$ TTC TGC TTG AGA GGT GCT GA -3'; interleukin-6 (IL-6) forward and reverse primers: $5^{\prime}$ - AGG AGA CTT GCC TGG TGA AA - $3^{\prime}$ and $5^{\prime}$ - CAG GGG TGG TTA TTG CAT CT $-3^{\prime}$; tumor necrosis factor- $\alpha$ (TNF- $\alpha$ ) forward and reverse primers: $5^{\prime}$-AGG CCT TGT GTT GTG TTT CCA-3' and 5' -TGG GGG ACA GCT TCC TTC TT-3'; and glyceraldehyde 3-phosphate dehydrogenase (GAPDH) forward and reverse primers: 5'-TGAAGGTCGGTGTGAACGGATTTGGC-3' and 5'-CATGTAGGCCATGA GGTCCACCAC-3'. The following PCR conditions were applied by 30 cycles of denaturation at $95{ }^{\circ} \mathrm{C}$ for $30 \mathrm{~s}$, annealing at $60{ }^{\circ} \mathrm{C}$ for $45 \mathrm{~s}$, and extension at $72{ }^{\circ} \mathrm{C}$ for
$1 \mathrm{~min}$. The cDNA was separated by electrophoresis on a $1 \%$ agarose gel for $60 \mathrm{~min}$ at $100 \mathrm{~V}$ and visualized by ethidium bromide. The bands of specific genes were normalized using GAPDH as reference.

\section{Statistical analysis}

All the results were expressed in mean \pm standard error. The difference in the results by each group was analyzed using IBM SPSS Statistic v. 21 (SPSS, Chicago, USA) and estimated at the level of $p<0.05$ by conducting Duncan's multiple range test.

\section{Results and discussion}

Cytotoxicity of ozonated krill oil in RAW 264.7 macrophages

The cytotoxicity of the ozonated krill oil in RAW 264.7 macrophages was estimated using the MTT assay at various concentrations $(10,50,100$, and $200 \mu \mathrm{g} / \mathrm{mL})$ of ozonated krill oil. The ozonated krill oil did not show significant cytotoxicity up to the concentrations of $100 \mu \mathrm{g} / \mathrm{mL}$ while cell cytotoxicity was observed at the concentration of $200 \mu \mathrm{g} / \mathrm{mL}$ (Fig. 1a). Thus, those concentrations $(10,50$, and $100 \mu \mathrm{g} / \mathrm{mL})$ were used in the subsequent experiments.

\section{Effect of ozonated krill oil on NO production in LPS-stimulated RAW 264.7 macrophages}

Macrophages play an important role in passive and active immunity and are involved in inflammatory response by being activated by a stimulus of LPS (Chelsky et al. 2015). In addition, activated macrophages produce enzymes, such as inducible nitric oxide synthase (iNOS) that is known to cause fatal results in a host by producing an inflammatory mediator, $\mathrm{NO}$ (Ulevitch and Tobias 1999; Akira et al. 2001). Macrophage-derived intercellular $\mathrm{NO}$ is a free radical with a short lifespan that plays an important role in the physiological and pathophysiological mechanisms in immune systems (Asamitsu et al. 2003). We evaluated the inhibitory effect of the ozonated krill oil on NO production to evaluate whether the ozonated krill oil exerts potential antiinflammatory effect in LPS-stimulated RAW 264.7 macrophages. As shown in Fig. 1b, NO production was substantially higher in LPS-stimulated cells that that in the untreated cells. However, ozonated krill oil treatment inhibited the effects of LPS in a dose-dependent manner. The addition of $100 \mu \mathrm{g} / \mathrm{mL}$ ozonated krill oil caused a $29 \%$ inhibition in LPS-stimulated NO production. Krill oil is a marine-derived oil rich in phospholipids, astaxanthin, and omega-3 polyunsaturated fatty acids (Costanzo et al. 2016). According to a previous study, astaxanthin is known to have an anti-inflammatory effect (Santos et al. 2012). In addition, Ohata et al. (1997) previously reported that suppression of NO production was observed with the omega-3 polyunsaturated fatty acids 

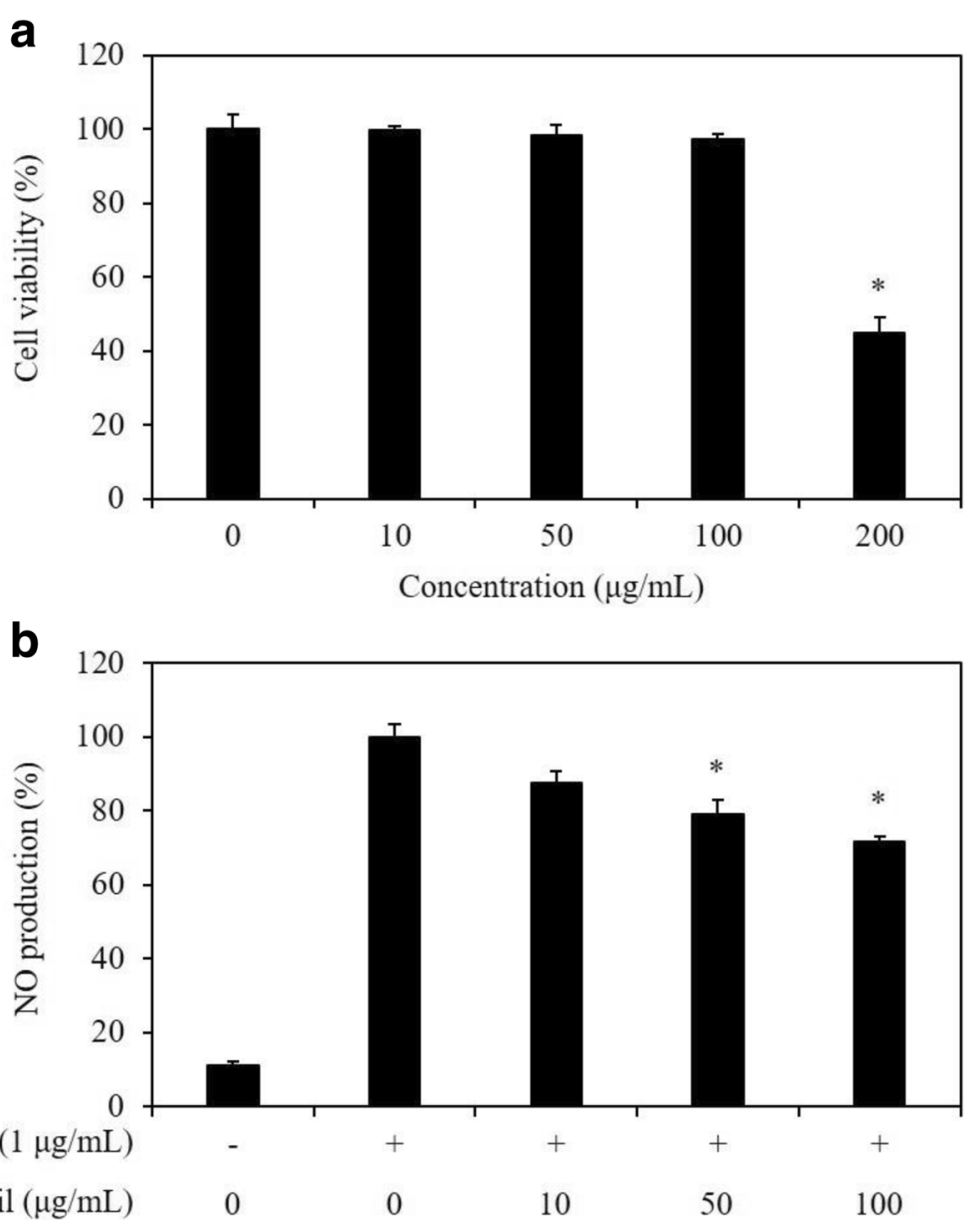

Fig. 1 a The effect of ozonated krill oil on cell viability in RAW 264.7 macrophages. The viability and cytotoxicity of cells was assessed by MTT assay. The optical density of the formazan generated in the untreated cells was considered to represent $100 \%$ viability. The data is expressed as mean percentages of the viable cells versus the untreated cells. $\mathbf{b}$ Effect of ozonated krill oil on LPS-stimulated production of NO in RAW 264.7 macrophages. Cells were stimulated with LPS $(1 \mu \mathrm{g} / \mathrm{ml})$ in the presence of ozonated krill oil $(10,50$, and $100 \mu \mathrm{g} / \mathrm{mL})$ for $24 \mathrm{~h}$ at $37^{\circ} \mathrm{C}$. Culture media were collected in order to measure NO production using the Griess reaction. Values are expressed as means \pm S.D. of triplicate experiments. ${ }^{*} p<0.05$ indicates significant differences from the LPS-stimulated group

such as DHA and EPA in a dose-dependent manner. Thus, these results supported the idea that the inhibitory effect of ozonated krill oil on NO production was mainly originated from its abundant $n$ - 3 high unsaturated fatty acids. According to the results of previous studies, ozone has been demonstrated to possess an anti-inflammatory effect (Delgado-Roche et al. 2017; Simonetti et al. 2017). Therefore, subsequent experiments for evaluating the anti-inflammatory effects and elucidating its action mechanisms were performed using ozonated krill oil.

Effect of the ozonated krill oil on iNOS and COX-2 expression in LPS-stimulated RAW 264.7 macrophages

Inflammatory processes were mediated by multiple molecular mechanisms. iNOS and COX-2 play a significant role in immunity against infectious factors by producing an amount of $\mathrm{NO}$ and $\mathrm{PGE}_{2}$, respectively (Akira et al.
2001). These enzymes have attracted attention for their detrimental roles in inflammation-related diseases (Yun et al. 1996; Kim et al. 2009). It has been known that iNOS induces NO production, which leads to inflammation (Liu and Hotchkiss 1995), and COX-2 is a significant mediator of inflammation involved in the $\mathrm{NO}$ group (Kim et al. 2014). Thus, inhibition of iNOS and COX-2 expression is a pivotal goal in the treatment of inflammatory diseases. Western blotting and RT-PCR were performed to determine whether the inhibitory effects of ozonated krill oil on NO production were related to the expression of iNOS and COX-2. The ozonated krill oil significantly inhibited the LPS-stimulated increases in the protein and mRNA expression of iNOS and COX-2 in a dose-dependent manner (Fig. 2). According to the previous study, treatment of krill oil inhibited the LPS-stimulated expression of iNOS and 


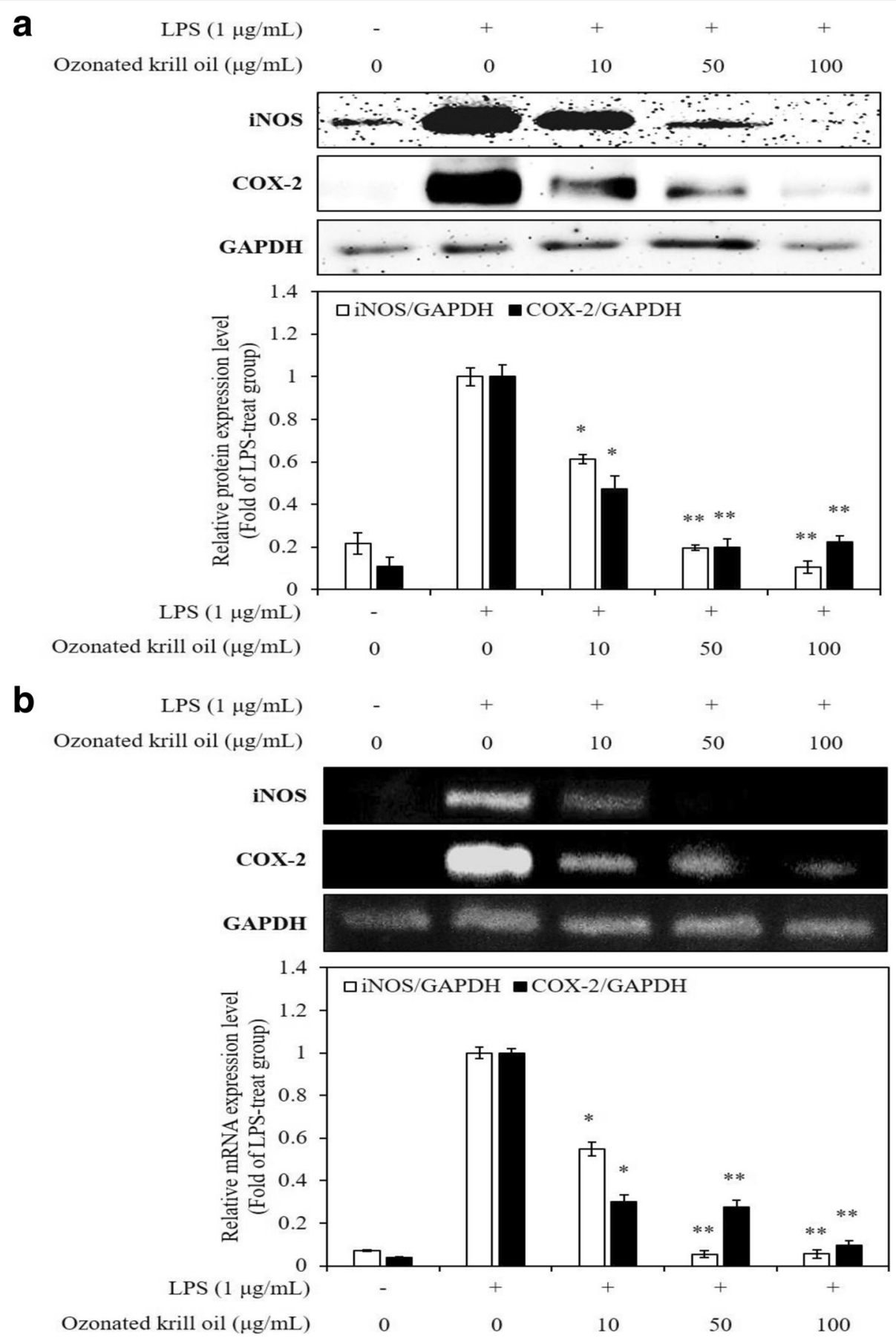

Fig. 2 Effect of ozonated krill oil on LPS-stimulated expression of iNOS and COX-2 in RAW 264.7 macrophages. Cells were stimulated with LPS (1 $\mu \mathrm{gg} / \mathrm{mL}$ ) in the presence of ozonated krill oil $(10,50$, and $100 \mu \mathrm{g} / \mathrm{mL})$ for $24 \mathrm{~h}$ at $37^{\circ} \mathrm{C}$. The expression of levels of iNOS and COX-2 a protein and $\mathbf{b}$ mRNA were measured using western blot and by RT-PCR analysis, respectively. iNOS and COX-2 versus GAPDH were measured by a densitometer. The density ratio of the protein and mRNA expressed in the LPS-stimulated group were considered to represent onefold. The data is expressed as mean folds of the protein and mRNA expression versus LPS-stimulated group. Values are expressed as means \pm S.D. of triplicate experiments. ${ }^{*} p<0.05$ and ${ }^{* *} p<0.01$ indicate significant differences from the LPS-stimulated group

COX-2 in mice brain (Choi et al. 2017). In addition, EPA and DHA modulate the expression of several inflammatory factors such as iNOS and COX-2, which subsequently lowers the induction of inflammation in cells (Allam-Ndoul et al. 2016; Mullen et al. 2010). These results suggest that ozonated krill oil principally acts by regulating NO production at the transcriptional level and that it could be an inhibitor of macrophage activation. 
Effects of ozonated krill oil on pro-inflammatory cytokine expression in LPS-stimulated RAW 264.7 macrophages The pro-inflammatory cytokines including TNF- $\alpha$, IL$1 \beta$, and IL- 6 mediate and regulate immunity and inflammation during the inflammatory process (Trikha et al. 2003; Huang et al. 2006). These cytokines play key roles in the induction of inflammatory process (Kim et al. 2016). Among the several inflammatory cytokines, TNF$\alpha$ is known to synthesize in the macrophages, and it stimulates the production of other inflammatory cytokines, such as IL-1 $\beta$ and IL-6 (Aggarwal and Natarajan 1996). IL-1 $\beta$ and IL-6 are well-known major pathogenic factors for many inflammatory diseases and regarded as endogenous mediators of LPS-stimulated fever (Ko and Jeon 2015). Because of their major roles in inflammatory response, reduction of several pro-inflammatory cytokines is of utmost importance during anti-inflammatory treatment. Thus, we determined the effects of ozonated krill oil on the mRNA expression of IL-1 $\beta$, IL- 6 , and TNF- $\alpha$ in LPS-stimulated macrophages. RT-PCR was performed to determine whether ozonated krill oil reduces the expression of the pro-inflammatory cytokines at the mRNA expression level. All mRNA expression levels of genes related with pro-inflammatory cytokines were increased by the stimulation with LPS, and the levels were significantly decreased by ozonated krill oil treatment in a dose-dependent manner (Fig. 3). This result demonstrated that ozonated krill oil effectively inhibits the production of pro-inflammatory cytokines that are paramount in the production of an inflammatory response in activated macrophages.

\section{Effect of ozonated krill oil on MAPKs activation in LPS-stimulated in RAW 264.7 macrophages}

The expression of various inflammatory mediators activates phagocytosis of external factors and is involved in inflammatory response through the activation of various inflammatory signaling network including a transcription factor, mitogen-activated protein kinases (MAPKs) (Akira et al. 2001). MAPKs, including JNK, extracellular signal-regulated kinase (ERK), and p38 kinase promote expression levels of iNOS and COX-2 in LPS-stimulated

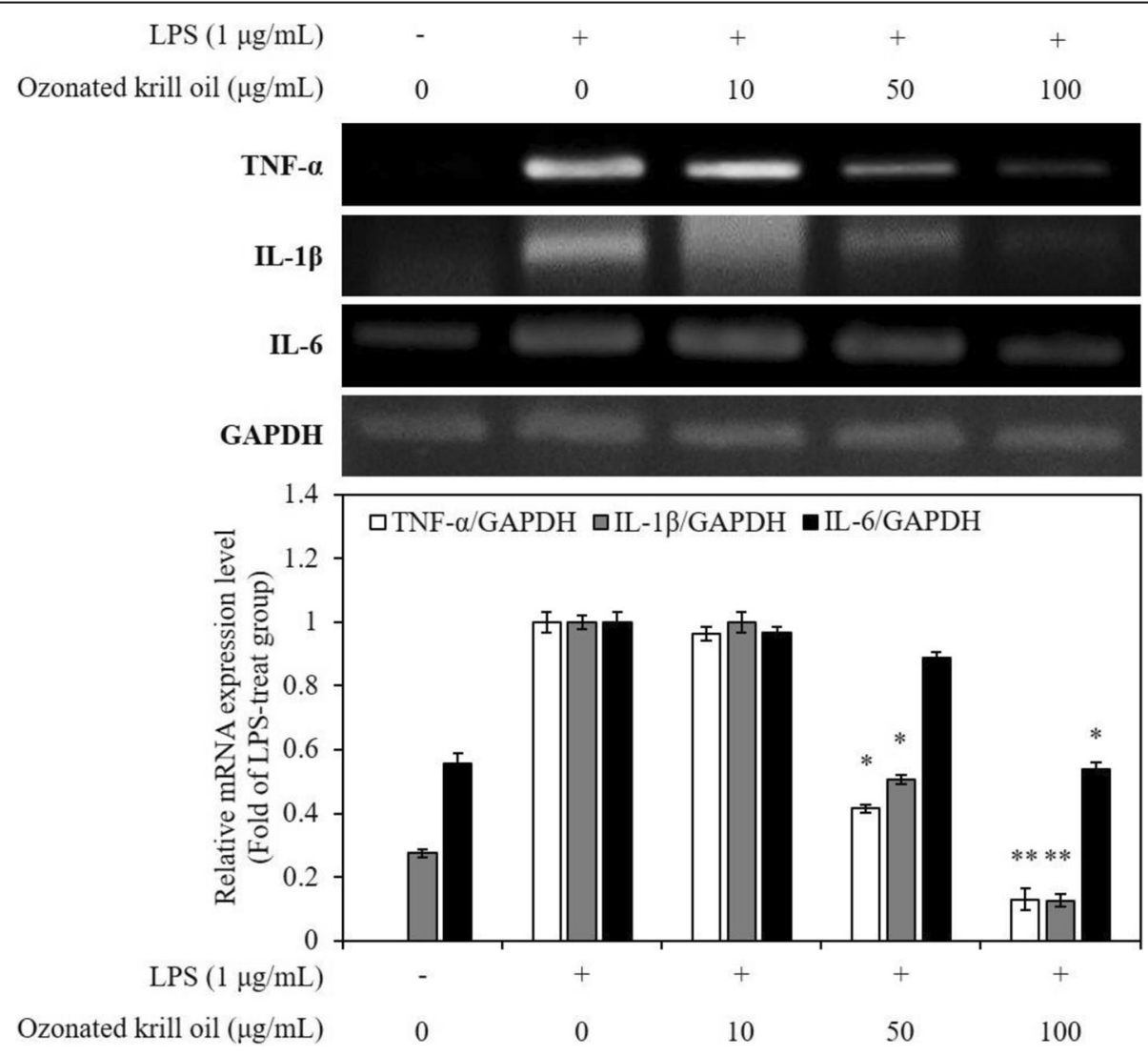

Fig. 3 Effect of ozonated krill oil on LPS-stimulated expression of TNF-a, IL-1 $\beta$, and IL-6 in RAW 264.7 macrophages. Cells were stimulated with LPS $(1 \mu \mathrm{g} / \mathrm{mL})$ in the presence of ozonated krill oil $(10,50$, and $100 \mu \mathrm{g} / \mathrm{mL})$ for $24 \mathrm{~h}$ at $37^{\circ} \mathrm{C}$. The expression of levels of pro-inflammatory cytokines mRNA were measured by RT-PCR analysis. TNF- $a$, IL-1 $\beta$, and IL- 6 versus GAPDH were measured via densitometry. The density ratio of the mRNA expressed in the LPS-stimulated group was considered to represent onefold. The data is expressed as mean folds of the protein and mRNA expression versus LPS-stimulated group. Values are expressed as means \pm S.D. of triplicate experiments. ${ }^{*} p<0.05$ and ${ }^{* *} p<0.01$ indicate significant differences from the LPS-stimulated group 
macrophages (Kyriakis and Avruch 2012). Moreover, activation of MAPKs induces production of proinflammatory cytokines, including IL-1 $\beta$, IL-6, and TNF$\alpha$ in LPS-stimulated macrophages (Ajizian et al. 1999). Thus, suppression of MAPK activation or function is a major mechanism. Therefore, in order to evaluate the action mechanism of ozonated krill oil on other inflammatory pathway besides pro-inflammatory cytokines, we investigated the effect of the ozonated krill oil on the activation of MAPKs in LPS-stimulated macrophages using western blot analysis. This result indicated that ozonated krill oil inhibited LPS-stimulated p38 MAPK and JNK phosphorylation, but not that of ERK, in RAW 264.7 macrophages (Fig. 4). These results suggest that the suppression of p38 MAPK and JNK phosphorylation might be involved in the inhibition of pro-inflammatory mediators and cytokines in LPS-stimulated RAW 264.7 macrophages.

\section{Conclusions}

Ozonated krill oil was prepared by the treatment using ozone gas, and its anti-inflammatory effect was evaluated in LPS-stimulated RAW 264.7 macrophages. The ozonated krill oil exhibited the inhibitory effect on NO production. Ozonated krill oil also reduced the mRNA expression of IL- $1 \beta$, IL- 6 , and TNF- $\alpha$ in LPS-stimulated RAW 264.7 macrophages. These effects are exerted by blocking phosphorylation of p38 MAPK and JNK. These findings provide a partial molecular explanation for the anti-inflammatory properties of ozonated krill oil.

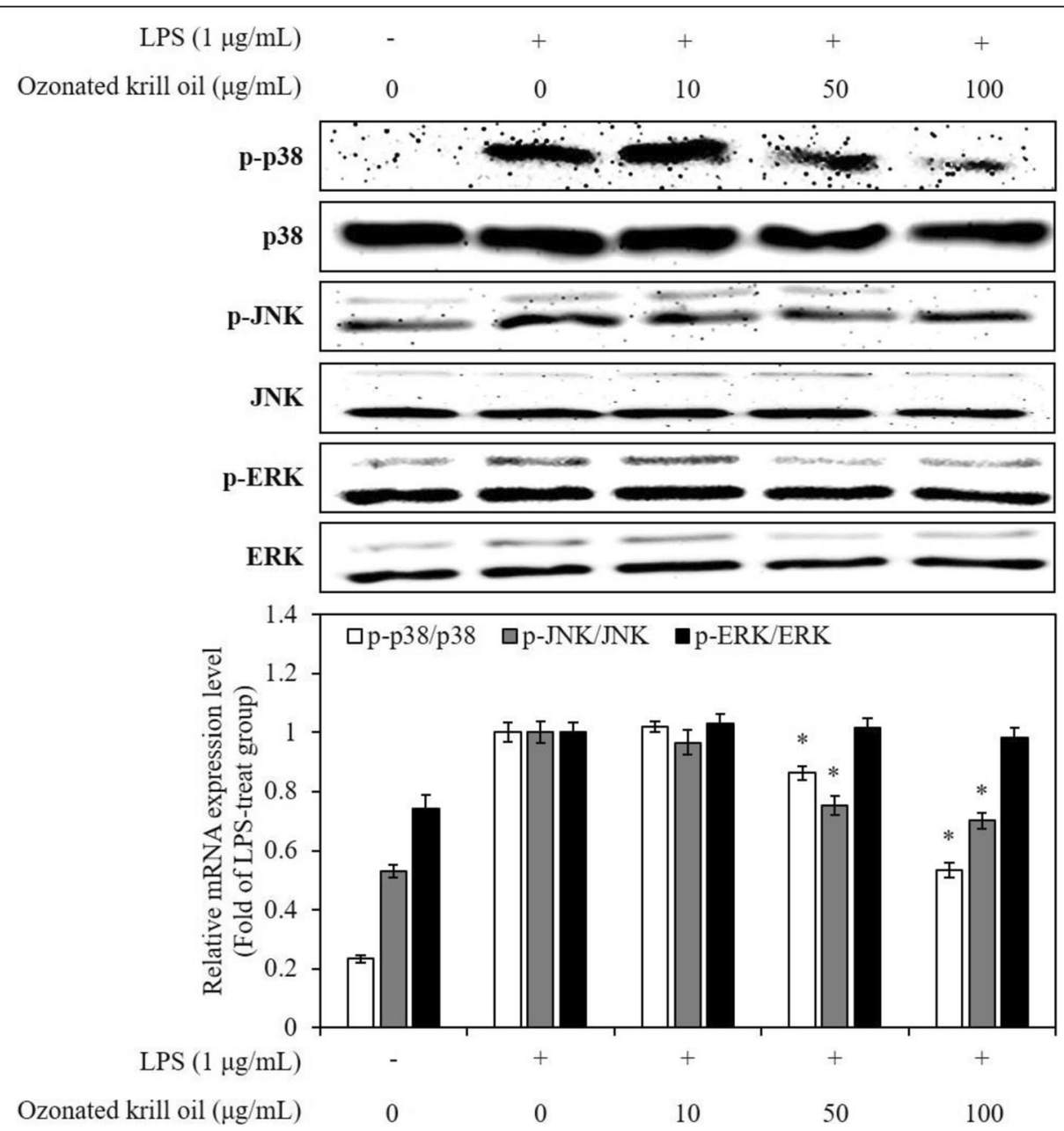

Fig. 4 Inhibitory effect of ozonated krill oil on LPS-stimulated phosphorylation of p38, JNK, and ERK in RAW 264.7 macrophages. Cells were stimulated with LPS $(1 \mu \mathrm{g} / \mathrm{mL})$ in the presence of ozonated krill oil $(10,50$, and $100 \mu \mathrm{g} / \mathrm{mL})$ for $24 \mathrm{~h}$ at $37^{\circ} \mathrm{C}$. The expression of levels of p38, JNK, and ERK were measured by western blot analysis. The density ratio of the protein expressed in the LPS-stimulated group was considered to represent onefold. The data is expressed as mean folds of the protein expression versus LPS-stimulated group. Values are expressed as means \pm S.D. of triplicate experiments. ${ }^{*} p<0.05$ indicate significant differences from the LPS-stimulated group 


\section{Abbreviations}

CDNA: Complementary deoxyribonucleic acid; COX-2: Cyclooxygenase-2; CVD: Cardiovascular disease; DHA: Docosahexaenoic acid; DMEM: Dulbecco's modified Eagle's medium; DMSO: Dimethyl sulfoxide; ECL: Enhanced chemiluminescence; EPA: Eicosapentaenoic acid; ERK: Extracellular signalregulated kinase; FBS: Fetal bovine serum; GAPDH: Glyceraldehyde 3phosphate dehydrogenase; Griess reagent: 1\% Sulfanilamide and $0.1 \%$ naphthylethylenediamine dihydrochloride in $2.5 \%$ phosphoric acid; IL13: Interleukin-1 $\beta$; IL-6: Interleukin-6; iNOS: Inducible nitric oxide synthase; JNK: c-Jun N-terminal kinases; LPS: Lipopolysaccharide; MAPKs: Mitogenactivated protein kinases; mRNA: Messenger ribonucleic acid; MTT: 3-(4,5Dimethyl-thiazol-2-yl)-2,5-diphenyltetrazolium bromide; NO: Nitric oxide; PUFAs: Polyunsaturated fatty acids; ROS: Reactive oxygen species; RTPCR: Reverse transcription-polymerase chain reaction; SDS: Sodium dodecyl sulfate; TBS-T: Tris-buffered saline with Tween 20; TNF-a: Tumor necrosis factor-a; UFAs: Unsaturated fatty acids

\section{Acknowledgements}

Not applicable.

\section{Funding}

This work was supported by a Research Grant of Pukyong National University (2017 year).

\section{Availability of data and materials}

Not applicable.

\section{Authors' contributions}

HDK and SBL designed this study and drafted the manuscript. YMK, WKJ, SCK, and SBK conceived and designed the study, and also revised the manuscript. All authors read and approved the final manuscript.

\section{Ethics approval and consent to participate}

Not applicable.

\section{Consent for publication}

Not applicable.

\section{Competing interests}

The authors declare that they have no competing interests.

\section{Publisher's Note}

Springer Nature remains neutral with regard to jurisdictional claims in published maps and institutional affiliations.

\section{Author details}

'Department of Food Science and Technology, Pukyong National University, 45, Yongso-ro, Nam-gu, Busan 48513, Republic of Korea. ${ }^{2}$ Marine-Intergrated Bionics Research Center, Pukyong National University, Busan 48513, Republic of Korea. ${ }^{3}$ Department of Biomedical Engineering, Pukyong National University, Busan 48513, Republic of Korea.

\section{Received: 28 December 2017 Accepted: 27 February 2018}

\section{Published online: 08 June 2018}

\section{References}

Aggarwal BB, Natarajan K. Tumor necrosis factors: developments during the last decade. Eur Cytokine Netw. 1996;7:93-124.

Ajizian SJ, English BK, Meals EA. Specific inhibitors of p38 and extracellular signalregulated kinase mitogen-activated protein kinase pathways block inducible nitric oxide synthase and tumor necrosis factor accumulation in murine macrophages stimulated with lipopolysaccharide and interferon-ү. J Infect Dis. 1999:179:939-44.

Akira S, Takeda K, Kaisho T. Toll-like receptors: critical proteins linking innate and acquired immunity. Nat Immunol. 2001;2:675-80.

Allam-Ndoul B, Guenard F, Barbier O, Vohl MC. Effect of n-3 fatty acids on the expression of inflammatory genes in THP-1 macrophages. Lipids Health Dis. 2016;15:69-76.

Asamitsu K, Tetsuka T, Kanazawa S, Okamoto T. RING finger protein AO7 supports NF-kappa B-mediated transcription by interacting with the transactivation domain of the p65 subunit. J Biol Chem. 2003;278:26879-87.
Barros MP, Poppe SC, Bondan EF. Neuroprotective properties of the marine carotenoid astaxanthin and omega-3 fatty acids, and perspectives for the natural combination of both in krill oil. Nutrients. 2014;6:1293-317.

Berge K, Musa-Veloso K, Harwood M, Hoem N, Burri L. Krill oil supplementation lowers serum triglycerides without increasing low-density lipoprotein cholesterol in adults with borderline high or high triglyceride levels. Nutr Res. 2014;34:126-33.

Berge K, Piscitelli F, Hoem N, Silvestri C, Meyyer I, Banni S, Di Marzo V. Chronic treatment with krill powder reduces plasma triglyceride and anandamide levels in mildly obese men. Lipids Health Dis. 2013;12:78-86.

Campanati A, De Blasio S, Giuliano A, Ganzetti G, Giuliodori K, Pecora T, Consales V, Minnetti I, Offidani A. Topical ozonated oil versus hyaluronic gel for the treatment of partial- to full thickness second-degree burns: a prospective, comparative, single-blind, non-randomised, controlled clinical tiral. Burns. 2013;39:1178-83.

Chelsky ZL, Yue P, Kondratyuk TP, Paladino D, Pezzuto JM, Cushman M, Turkson J. A resveratrol analogue promotes ERK MAPK-dependent STAT3 serine and tyrosine phosphorylation alterations and antitumor effects in vitro against human tumor cells. Mol Pharmacol. 2015;88:524-33.

Choi JY, Jang JS, Son DJ, Im HS, Kim JY, Park JE, Choi WR, Han SB, Hong JT. Antarctic krill oil diet protects against lipopolysaccharide-induced oxidative stress, neuroinflammation and cognitive impairment. Int J Mol Sci. 2017;18:2554-69.

Costanzo M, Cesi V, Prete E, Negroni A, Palone F, Cucchiara S, Oliva S, Leter B, Stronati L. Krill oil reduces intestinal inflammation by improving epithelial integrity and impairing adherent-invasive Escherichia coli pathogenicity. Dig Liver Dis. 2016;48:34-42.

Delgado-Roche L, Riera-Romo M, Mesta F, Herández-Matos Y, Barrios JM, Martínez-Sánchez G, Al-Dalaien SM. Medical ozone promotes Nrf2 phosphorylation reducing oxidative stress and pro-inflammatory cytokines in multiple sclerosis patients. Eur J Pharmacol. 2017;811:148-54.

Deutsch L. Evaluation of the effect of Neptune krill oil on chronic inflammation and arthritic symptoms. J Am Coll Nutr. 2007;26:39-48.

Fasano E, Serini S, Mondella N, Trombino S, Celleno L, Lanza P, Cittadini A, Calviello G. Antioxidant and anti-inflammatory effects of selected natural compounds contained in a dietary supplement on two human immortalized keratinocyte lines. Biomed Res Int. 2014;2014:327452-65.

Guerra-Blanco P, Poznyak T, Pérez A, Gómez YM, Bautista-Ramírez ME, Chairez I. Ozomation degree of vegetable oils as the factor of their anti-inflammatory and wound-healing effectiveness. Ozone Sci Eng. 2017;39:374-84.

Huang TH, Tran VH, Duke RK, Tan S, Chrubasik S, Roufogalis BD, Duke CC. Harpagoside suppresses lipopolysaccharide induced iNOS and COX-2 expression through inhibition of NF-kappa B activation. J Ethnopharmacol. 2006;104:149-55.

Kim AR, Shin TS, Lee MS, Choi JS, Jang BC, Byun DS, Park NK, Kim HR. Isolation and identification of phlorotannins from Ecklonia stolonifera with antioxidant and anti-inflammatory properties. J Agric Food Chem. 2009;57:3483-9.

Kim KN, Ko SC, Ye BR, Kim MS, Kim J, Ko EY, Cho SH, Kim D, Heo SJ, Jung WK. 5-Bromo-2-hydroxy-4-methyl-benzaldehyde inhibited LPS-induced production of pro-inflammatory mediators through the inactivation of ERK, p38, and NF-KB pathways in RAW 264.7 macrophages. Chem Biol Interact. 2016;258:108-14.

Kim SY, Kim EA, Kang MC, Lee JH, Yang HW, Lee JS, Lim TI, Jeon YJ. Polyphenolrich fraction from Ecklonia cava (a brown alga) processing by-product reduces LPS-induced inflammation in vitro and in vivo in a zebrafish model. Alage. 2014;29:165-74.

Ko SC, Jeon YJ. Anti-inflammatory effect of enzymatic hydrolysates from Styela clava flesh tissue in lipopolysaccharide-stimulated RAW 264.7 macrophages and in vivo zebrafish model. Nutr Res Prac. 2015;9:219-26.

Kyriakis JM, Avruch J. Mammalian MAPK signal transduction pathways activated by stress and inflammation: a 10 year update. Physiol Rev. 2012;92:689-737.

Lee MF, Lai CS, Cheng AC, Hou JS, Badmaev V, Ho CT, Pan MH. Krill oil and xanthigen separately inhibits high fat diet induced obesity and hepatic triacylglycerol accumulation in mice. J Func Foods. 2015;19:913-21.

Liu RH, Hotchkiss JH. Potential genotoxicity of chronically elevated nitric oxide: a review. Mutat Res. 1995;339:73-89.

Mosmann T. Rapid colorimetric assay for cellular growth and survival: application to proliferation and cytotoxicity assays. J Immunol Methods. 1983;65:55-63.

Mullen A, Loscher CE, Roche HM. Anti-inflammatory effects of EPA and DHA are dependent upon time and dose-response elements associated with LPS stimulation in THP-1-derived macrophages. J Nutr Biochem. 2010;21:444-50. 
Nogales CG, Ferrari PA, Kantorovich EO, Lage-Marques JL. Ozone therapy in medicine and dentistry. J Contemp Dent Pract. 2008;4:75-84.

Ohata T, Fukuda K, Takahashi M, Sugimura T, Wakabayashi K. Suppression of nitric oxide production in lipopolysaccharide-stimulated macrophage cells by omega 3 polyunsaturated fatty acids. Jpn J Cancer Res. 1997;88:234-7.

Santos SD, Cahú TB, Firmino GO, de Castro CCMMB, Carvalho LB Jr, Bezerra RS, Filho JLL. Shrimp waste extract and astaxanthin: rat alveolar macrophage, oxidative stress and inflammation. J Food Sci. 2012;77:141-6.

Shoukheba MYM, Ali SA. The effects of subgingival application of ozonated olive oil gel in patient with localized aggressive periodontitis. A clinical and bacteriological study. Tanta Dent J. 2014;11:63-73.

Simonetti V, Quagliariello V, Giustetto P, Franzini M, laffaioli RV. Association of ozone with 5-fluorouracil and cisplatin in regulation of human colon cancer cell viability: in vitro anti-inflammatory properties of ozone in colon cancer cells exposed to lipopolysaccharides. Evid Based Compl Alt Med. 2017;2017:1-6.

Ulevitch RJ, Tobias PS. Recognition of gram-negative bacteria and endotoxin by the innate immune system. Curr Opin Immunol. 1999;11:19-22.

Tou JC, Jaczynski J, Chen YC. Krill for human consumption: nutritional value and potential health benefits. Nutr Rev. 2007;65:63-77.

Trikha M, Corringham R, Klein B, Rossi JF. Targeted antiinterleukin-6 monoclonal antibody therapy for cancer: a review of the rationale and clinical evidence. Clin Cancer Res. 2003;9:4653-65.

Valacchi G, Zanardi I, Lim Y, Belmonte G, Miracco C, Sticozzi C, Bocci V, Travagli V. Ozonated oils as functional dermatological matrices: effects on the wound healing process using SKH1 mice. Int J Parm. 2013:458:65-73.

Virtue P, Johannes RE, Nichols PD, Young JW. Biochemical composition of Nyctiphanes australis and its possible use as an aquaculture feed source: lipids, pigments and fluoride content. Mar Biol. 1995;122:121-8.

Weissman BA, Gross SS. Measurement of NO and NO synthase. Curr Protoc Neurosci. 2001;7:13.

Xie D, Jin J, Sun J, Liang L, Wang X, Zhang W, Wang X, Jin Q. Comparison of solvents for extraction of krill oil from krill meal: lipid yield, phospholipid content, fatty acids composition and minor components. Food Chem. 2017 233:434-41.

Yun HY, Dawson TT, Dawson TM. Neurobiology of nitric oxide. Crit Rew Neurobiol. 1996;19:291-316.

Zhu J, Zhuang P, Luan L, Sun Q, Cao F. Preparation and characterization of novel nanocarriers containing krill oil for food application. J Func Foods. 2015;19:902-12.

\section{Submit your next manuscript to BioMed Central and we will help you at every step:}

- We accept pre-submission inquiries

- Our selector tool helps you to find the most relevant journal

- We provide round the clock customer support

- Convenient online submission

- Thorough peer review

- Inclusion in PubMed and all major indexing services

- Maximum visibility for your research

Submit your manuscript at www.biomedcentral.com/submit 